\title{
Composición social y caracterización de las principales sociedades culturales y de instrucción y recreo en la región de Cienfuegos entre 1840 y 1899
}

\author{
Victoria Maria Sueiro Rodríguez *
}

\section{RESUMEN}

En el trabajo se ofrece un recuenio histórico de las principales sociedades culturales y de instrucción $y$ recreo de la región de Cienfuegos en la segunda mitad del siglo xIx; se caracterizan estas asociaciones atendiendo a las razas, clases $y$ población en ellas representadas, destacando aquellas que tuvieron una mayor incidencia en el desarrollo cultural, artístico y literario de

Cienfuegos en estos años.

Se hace alusión al incremento del número de sociedades existentes en la región a partir de julio de 1888 , fecha en que fue promulgada en Cuba la Ley de Asociaciones, coincidiendo con el periodo de mayor prosperidad de la economía cienfueguera, lo que coadyuvó al incremento no sólo de sociedades culturales, sino también de sociedades de diversos tipos

\section{ABSTRACT}

Throughout this work, a historical reckon up is shown about the main cultural societies, instruction and recreation in Cienfuegos by the second half of the 19th century. These societies are characterized taking into account human race, classes and population which are stood out those that had a major incidence on the cultural, literary and artistic development of Cienfuegos by those years.

This work is also abouth the increase of number of societies which existed in Cienfuegos region from July of 1888 . Such date coincides with the promulgation of the Associations Law in Cuba; it also drove to the increase not only of the cultural societies and recreation coincides with the period of major economic prosperity in Cienfuegos that, but also of different kinds.

* Universidad Pedagógica de Cienfuegos. Cuba. 


$\begin{aligned} \text { PALABRAS CLAVE } & \text { KEYWORDS } \\ \text { Asociacionismo; Sociedades de } & \text { Associationism, Societies of Instruction } \\ \text { instrucción y recreo; Sociedades } & \text { and Recreation, Cultural Societies, } \\ \text { culturales; Estudios regionales y } & \text { Regional and Local Studies, Regional } \\ \text { locales; Sociedades regionales } & \text { Spanish Societies, Cientuegos } \\ \text { españolas, Sociedades cienfuegueras, } & \text { Societies, Societies-History-19th } \\ \text { Sociedades: Historia-siglo xIX. } & \text { Century. }\end{aligned}$

Las regiones y localidades cubanas reclaman cada vez mayor atención. Estas han comenzado a trabajar por el rescate de su identidad, para lo cual ameritan el conocimiento de su pasado, requisito indispensable para comprender y cambiar el presente y conducir su futuro.

En este sentido, estudiar el problema de la repercusión que tuvieron las instituciones y asociaciones culturales y de instrucción y recreo en la localidad de Cienfuegos, permitirá comprender el papel jugado por estas sociedades como difusoras y promotoras de la cultura cienfueguera en el periodo colonial, destacando en ellas el sentimiento de pertinencia e identificación regionales.

La jurisdicción de Cienfuegos, parte componente de la antigua región villaclareña en el siglo Xix, experimentó un vertiginoso desarrollo cultural condicionado por las favorables condiciones económicas que presentó la villa desde sus primeros años de existencia ${ }^{1}$. Esto posibilitó que a Cien-

Desde fecha temprana, a partir del llamado Boom azuarero, el asociacionismo se hizo sentir en la región cienfueguera, pues el despegue hacia el desarrollo económico que fue característico de la zona, posibilitó que “las empresas comerciales emergentes en Cienfuegos consolidadas con el desarrollo azucarero se constituyeran como sociedades de tipo burgués capitalista. Habian iniciado la acumulación originaria de capital. Organizadas por hombres emprendedores, saqueadores de riquezas naturales o humanas - como maderero se inicia Avilés, como negrero Tomás Terry-, especuladores, contrabandistas, usureros, impulsados por su afán de lucro llegarán a acumular grandes reservas en efectivo" (Tomado de Violeta Rovira González. "Apuntes sobre la organización de la economia cienfueguera y significación de los franceses fundadores en ella: Introducción a la Historia de Cienfuegos, 1819-1860", Islas (52/53):47, sept. 1975-abril de 1976).

Citemos en este caso la Casa Comercial de Avilés y Leblanc, que llegó a ser junto con la de Terry una de las más poderosas de Cienfuegos; la Sociedad Fowler y Prosper, la Sociedad Abreu, Jova y Cía, Roig y Segerica, Apezteguia, Arrechea y Zaldo; Gándara, Lomba y Cía, Sociedad Torriente, Grove y Cía, Sociedad Torriente y Hermanos.

Según señala Violeta Rovira todos estos comerciantes "constituyeron el elemento dinámico, verdaderamente burgués de Cienfuegos" ( $p .49$ ), los que unidos a otros hacendados de diversos lugares del país como los « reputadísimos negreros" Julián Zulueta y Pedro Blanco da la medida de la importancia del boom regional» (Orlando Garcia Martínez. "Estudio de la economía cien. fueguera desde la fundación de la colonia Fernandina de Jagua hasta mediados del siglo $x \mid x "$. Islas (55/56):143, sept./1976-abril de 1977).

Para ampliar sobre este aspecto consulté, además de los trabajos citados, el titulado "Cienfuegos: siglo XIX, un peculiar proceso de concentración y centralización en la industria azucarera», 
fuegos llegara un flujo constante de hombres de negocio, intelectuales, profesionales, etc; que a la par de realizar sus actividades laborables, buscaran en la sociedad un espacio donde pudieran agruparse. Estos espacios fueron precisamente las diferentes asociaciones e instituciones que se crearon, entre otros objetivos, con el fin de descansar, aprovechar el tiempo libre y recrearse de la forma más culta posible.

Todas las sociedades e instituciones culturales surgidas en Cuba durante el siglo XIX tomaron como patrón más o menos lejano a los modelos antiguos, fundamentalmente los de Grecia ${ }^{2}$. De esta manera, las sociedades cubanas entroncaron con una rica y antiquísima tradición cultural universal.

En Cienfuegos, cuando sólo habían transcurrido tres décadas de su fundación ya existían dos sociedades: la sociedad Recreo (1841) y el Liceo Artístico y Literario (1847) surgido seis años más tarde que el habanero.

En 1850 se crea la Sociedad Filarmónica Cienfueguera producto de la fusión de estas 2 sociedades; “(...) mirada como antiespañola, las autoridades militares la tenían en gran acecho y, muchos socios, personas de gran relieve social, fueron llevados de sus salas a la investigación de la policia y castigados como infidentes al régimen dominante. Asi, no fué extraño que fuera muriendo esa sociedad criollísima y que, en mayo de 1869 , prácticamente, no existiera ${ }^{3}$ (sic).

Al igual que en la Filarmónica habanera, en la cienfueguera se hacía derroche de lujo y elegancia. Uno de sus miembros al referirse al tema expresó: «El lujo, según el sentir de un amigo nuestro, va ocupando un lugar preferente en los salones filarmónicos, y si esto llega a ser verdad lo sentiremos infinito, porque de ese modo, la numerosa concurrencia que hoy favorece a la sociedad Filarmónica irá en decadencia" (sic) ${ }^{4}$.

Las filarmónicas constituyeron uno de los primeros indicios de independencia en el plano cultural de los criollos. A la Filarmónica cienfue-

de Orlando García Martínez (inédito) y los trabajos de Hernán Venegas y Carmen Guerra Díaz relacionados con la economía cienfueguera en estos años que han sido publicados en las páginas de la revista Islas.

2 Véase el libro de Edita Caveda Romani. Historia de las Sociedades de instrucción y recreo surgidas en Cuba a finales del siglo xVIII, durante el siglo xix y primeras décadas del xx. Ciudad de La Habana: Centro de Investigación y Desarrollo de la Cultura Cubana Juan Marinello, 1979 (inédito), 10 relativo a las sociedades en la antigua Grecia.

Rodriguez Altunaga, Rafael. Las Villas: Biografía de una provincia. La Habana: /s.n/ 1955, pp. 197-198.

4 El Telégrafo (Cienfuegos) 12-12-1865 (34): 3. 
guera pertenecian hombres de la raza blanca vinculados a la clase económicamente dominante en la región, y españoles residentes en la localidad. Si se revisan las listas de socios se pueden encontrar a personalidades que representaban al Gobierno Español en la región y nombres como los de: Agustín Goytisolo, Antonio Terry, Félix Bouyón, Eduardo Terry, Esteban Torriente, etc.

El local social de esta sociedad durante sus 19 años de existencia estuvo ubicado en la calle Argüelles entre Hourruitiner y Gacel ${ }^{5}$. Era una sociedad, que según sus estatutos estaba bajo el patrocinio de los señores gobernadores de la villa y sus principales objetivos fueron:

1. Fomentar el espíritu de asociación, proporcionando a los socios un punto de continua y recíproca comunicación entre los más agradables y lícitos pasatiempos.

2. El adelanto de la juventud en aquellos ramos de las bellas artes cuyo cultivo le permitiera el desarrollo de la sociedad.

Esta institución a pesar de los propósitos que se trazó, tuvo sus limitaciones pues sólo la cultura llegaba a sus socios, por lo que refleja el carácter clasista y elitista de la sociedad colonial cubana.

La Sociedad Filarmónica durante 19 años fue el único centro cultural que tuvo la villa, y en este lapso de tiempo todas las actividades culturales se congregaron en sus salones, las tertulias, conciertos y las funciones literarias y dramáticas eran muy frecuentes en los salones de esta institución. Además, se puso una cátedra de instrucción y se ofrecían clases, muchas de las cuales estuvieron a cargo del destacadísimo profesor gaditano radicado en Cienfuegos Mariano Dumas Chancel.

En el seno de esta sociedad se fundó la primera orquesta que tuvo la villa dirigida por el músico Tomás Tomás D'Clouet y se estableció la primera Academia de música con destacados profesores como Joaquín Soret (español) Félix Varona y el mencionado Tomás.

Del año 1865 data la aparación de la Academia Literaria de Artesanos fundada el 8 de agosto del citado año, la que fue creada con un fin netamente educacional. La apertura de esta academia en la localidad cienfueguera se corresponde con la etapa en que aparece la llamada «aristocracia

5 Rousseau, P. L. Memoria descriptiva, histórica y biográfica de Cienfuegos y su jurisdicción y las fiestas del primer centenario de la fundación de la ciudad (1819-1919). La Habana: El Siglo xx, 1920 , p. 108. 
proletaria» ${ }^{6}$ y también se corresponde con la etapa en la que en España surgen los Ateneos Obreros dedicados a estos fines. Precisamente es en la década del 60 cuando surgen obreros cualificados que todavia presentaban características similares a las del artesanado tradicional; lo cual hizo posible que al amparo de estos grupos se fundaran muchos gremios y asociaciones de socorros mutuos. Esta academia «funcionó en la calle Argüelles, no 59 " ' y sus miembros eran representantes de la clase obrera.

La fundación del Casino Español en Cienfuegos como sociedad de recreo es del año 1869, coincidiendo con el momento de aparición de estos centros a escala nacional. En su origen, fue no un mero centro de reunión, instrucción y recreo, sino un club político donde España tenía representados sus intereses. Sus miembros eran dueños de grandes propiedades de tierra, de esclavos, de almacenes, de periódicos, etc. Poseían sobre la masa de nativos gran autoridad. Tenían una ideología reaccionaria y conservadora y agrupaba a peninsulares con estas ideas.

Refiriéndose a los Casinos Españoles señaló Juan G. Pumariega que fue socio del Casino Español de Cienfuegos «(...) que en ellos se practicaban todas las manifestaciones de la sociabilidad; que en sus reglamentos estaba prohibido tratar asuntos religiosos y políticos y todo aquello que pudiera apasionar excesivamente los ánimos" "

Razón esta que no funcionó en los primeros años de existencia del casino, por lo que fue preciso crear una nueva sociedad que respondiera a los intereses culturales de algunos de sus miembros, y es entonces que se decide la fundación del Casino Español de Artesanos, el 5 de junio de 1870. Su local estaba ubicado en la antigua casa de Don José Antonio Capote situada en Paseo de Vives (hoy Prado) entre Santa Cruz y Santa Clara, conocida con el nombre de Casa de los Leones. Esta institución tuvo una efímera vida, solo existió 10 años. En 1880 se reintegró al Casino Español.

En los años que siguieron a la Guerra de los Diez Años, la sociedad cubana evolucionó en sentido favorable. En toda Cuba empezó a desarrollarse el interés por las asociaciones de diversos tipos, cuya realización se basaba en propósitos colectivos de cultura, esparcimiento y so-

\footnotetext{
6 Portuondo, José Antonio. La Aurora y los comienzos de la prensa y de la organización obrera en Cuba. /s.l/: Imprenta Nacional de Cuba, 1961, p. 14.

El Telégrafo (Cienfuegos) 18 de julio de 1865. Citado en: La Correspondencia (Cienfuegos) 11-4-1958, año 60, n 135, p. 5. Sección Maremagnum.

8 Pumariega, Juan G. Importancia de las sociedades españolas en Cuba. La Habana: s.n., 1921 , p. 14
} 
corros mutuos. La guerra conmovió al país y muchas instituciones culturales resultaron quebrantadas, otras sufrieron vigilancia y represión, algunas cerraron sus puertas temporal o definitivamente, como fue el caso de la Filarmónica que se cerró en 1869 con el Levantamiento de Las Villas.

A partir de estos años, el volumen de emigrantes españoles en la región fue considerable, lo que posibilitó que se gestaran gran cantidad de asociaciones españolas de emigrantes. "En su mayoría son sociedades de beneficencia, aunque también se fundan de socorros mutuos» ${ }^{9}$.

Moisés LLordén en su acucioso estudio titulado «Las asociaciones españolas de emigrantes" plantea que "entre las primeras organizaciones de los distintos colectivos de inmigrantes europeos que surgen en América en el siglo XIX, se encuentran en lugar preferente para el caso español los de carácter lúdico-recreativo y cultural» ${ }^{10}$. La creación de estas sociedades en Cuba (de instrucción y recreo), «responde inicialmente a la necesidad que tiene el inmigrante de relacionarse con individuos de su mismo grupo étnico o nacionalidad, la de hablar un mismo idioma con sus compatriotas, o poder encontrar y ofrecer solidaridad en un país que no es el propio" "1.

Además, agrega, que "sus fundadores son, en su mayoría, inmigrantes - con poder económico o intelectual- pero que no participaban en igual grado del poder social o político en el ámbito territorial donde residían» ${ }^{12}$. Tal es el caso, del Casino Español de Cienfuegos. Estas asociaciones se limitaban generalmente a la tenencia de un local (no siempre en propiedad) donde se organizaban reuniones, tertulias y juegos diversos, así como los tradicionales actos sociales (bailes, banquetes, etc.). Entre los miembros del Casino Espanol se pueden citar a: José Pertierra, Nicolás Gamboa, Joaquín Cacicedo, Antonio Intriago, Ramón de la Torriente, Galo Rodríguez Olla -personalidades vinculadas al poder político y económico en la región- que fueron de aquellos que más se destacaron dentro de esta sociedad.

9 Entre las sociedades regionales españolas que se fundaron en Cienfuegos se pueden citar: la de "Beneficencia y socorros mutuos de naturales de Cataluña e islas Baleares" (1871-1875?); la de "Socorros mutuos La Montañesa" (1883), fundada por españoles provenientes de las provincias que pertenecian al antiguo reino de Castilla Vieja; la de "Beneficencia de naturales y oriundos de Galicia” (1876); la de "Beneficencia Asturiana" (1881) y la de "Beneficencia Canaria" (en 187-?).

10 LLORDÉn MINANAMBREs, Moisés. "Las asociaciones de emigrantes", en: Arte, cultura y Sociedad en la emigración española a América. Oviedo: Universidad de Oviedo, 1992, p. 29.

Idem, p. 29.

12 Idem, p. 31 
Otros tipos de sociedades fundadas fueron las de tipo cultural. De ellas se crearon tres instituciones en Cienfuegos, que se dedicaron por completo a la música: la sociedad coral Lira Catalana, el Orfeón Gallego Rumores del Miño y el Orfeón Nacional, las cuales tomaban participación en actos importantes de la región, fiestas, romerías, retretas, etc. Estas fueron creadas con los fines y propósitos de incrementar la cultura artística, especialmente el canto dentro de sus asociados y a los socios de otras instituciones, mediante cuadros artísticos de piano, canto, etc.

Muchas de estas sociedades españolas fundaron sus propias publicaciones como por ejemplo: "La Colonia Canaria» (1891), órgano de la Sociedad de beneficencia Canaria; "La Colonia Española» (1898), órgano de la Colonia Española de Cienfuegos; "La Fraternidad" (1898), órgano de la Colonia Española de Rodas; “El Clamor de Asturias" (1885), órgano de la Sociedad de Beneficencia Asturiana y «El Avisador Galaico» (1876), de la Sociedad de Beneficencia de Naturales y Oriundos de Galicia, primer periódico que circuló en la Isla en habla gallega.

En las publicaciones de estas sociedades regionales españolas, no sólo se hacía alusión a la vida interna de estas asociaciones, sino también a las particularidades de cada sociedad regional, así como a la labor de promoción cultural (artística, educativa, sanitaria y de ayuda benéfica realizadas por ellos en Cuba). Estas publicaciones son una muestra del quehacer sociocultural de esas sociedades en Cuba y representan una fuente de gran interés para reconstruir la historia de la presencia hispánica en Cienfuegos, así como sus costumbres y tradiciones y las que adquirieron aquí y su posterior proceso en el nuevo contexto sociocultural en el que se movían.

Estas colectividades españolas realizaban las tradicionales romerías donde cada una de ellas representaban a su región natal, desde los trajes hasta las actividades. Muy destacada fue la que se dio durante los días 6 y 7 de septiembre de 1885 en honor a la Virgen de Montserrat, donde se bailó el Copeo de Montaña (baile de las Islas Baleares, en cuya danza hay cierto peculiar sentido ritual con sedimentos ancestrales que existió a lo largo del siglo y por lo general se bailaba en las fiestas populares).

En 1879 surgió la sociedad de instrucción y recreo Liceo de Cienfuegos que fue en el desarrollo cultural de la localidad una de sus más prestigiosas instituciones. Instituto de arte en que se destacaba lo cubano, contribuyeron a su creación y celebridad criollos cienfuegueros del pasado siglo. Si se revisan sus actas, se encuentran en la lista de sus socios y en sus directivas, a educadores, poetas, literatos, doctores y notables disertantes. 
Los objetivos del Liceo fueron: fomentar las letras, las ciencias y las bellas artes, sostener clases gratuitas, ofrecer cursos de diferentes idiomas, propiciar la celebración de concursos literarios y juegos florales, ofrecer veladas líricas, dramáticas, conciertos, y en general, promover cualquier otro tipo de actividad cultural.

Al Liceo pertenecian las capas más cultas de la población blanca nativa. Entre sus miembros pueden citarse a: Leopoldo Díaz de Villegas, Eduardo Terry Dorticós, Isidro Castiñeyra Carbó, Víctor Vila, Antonio de León y José Terry, entre otros.

Sus locales sociales fueron trasladados en varias oportunidades. Su primer espacio social estuvo ubicado en la calle de Santa Cruz entre Hourruitiner y Gacel, luego se trasladó para los altos del Terry y en 1891 abrió sus puertas en el local que se construyó en un solar yermo al mencionado teatro ${ }^{13}$.

A esta institución concurrían personas ilustradas de la sociedad cienfueguera del pasado siglo y se distinguían sus socios por el sello de refinamiento y extremada cultura.

Esta sociedad a través de sus actividades tuvo períodos de prosperidad y decadencia, pero siempre el entusiasmo de sus miembros hizo posible que mantuviera la gloriosa historia patriótica y cubana que la caracterizaba. El Liceo fue cerrado por el Gobernador Civil Otero Pillado durante algún tiempo debido a las actividades revolucionarias que realizaban algunos de sus miembros, ya que a este liceo concurrían algunas personalidades cienfuegueras que se vincularon a la causa cubana, como fue el caso de Rita Suárez del Villar, conocida por «La Cubanita»; además, funcionaron clubes patrióticos.

Un aspecto importante a considerar dentro de esta sociedad es el hecho de la fundación del Club Revolucionario de Cienfuegos con carácter secreto a raíz de la muerte de José Martí, en 1895. Con anterioridad, en mayo de 1880, había aparecido "El Liceo" como órgano oficial de esta institución dirigida por Hilario $\mathrm{C}$. Brito y Emilio $\mathrm{C}$. de Villegas.

Al igual que en la mayoria de las sociedades cienfuegueras, el liceo contó con su propio teatro, debido a que según disposición fechada en Madrid en enero de 1860, en aquellas ciudades donde no existiera teatro oficial se considerase como tales a las sociedades y liceos por acciones.

13 Suetro Rodriguez, Victoria Maria. Cienfuegos 1850-1899: Notas para el estudio de las principales manifestaciones y asociaciones culturales en la antigua villa. Santa Clara: Universidad Central de Las Villas, 1988, pp. 64-65 (Trabajo de Diploma). 
Es así, que en casi todas las sociedades cubanas se establecieron pequeñas salas teatrales donde se representaron obras de dramaturgos del momento, tanto españoles como cubanos.

Muchas de estas instituciones no estuvieron ajenas a lo que acontecía en el orden político en el país. En este sentido, es válido destacar, la labor de las llamadas "sociedades de color" que también se fundaron en la localidad y la vinculación estrecha de éstas con el problema de la independencia cubana. Entre ellas se pueden mencionar: la sociedad de instrucciòn y recreo El Progreso (1879), inaugurada por hombres de la raza negra de una mejor posición social; se constituyó en la calle de Santa Cruz esquina a San Luis; la sociedad de instrucción y recreo La Amistad (1879) ubicada en Bouyón entre San Fernando y Argüelles. A esta sociedad pertenecian obreros negros y mulatos libres que tenían empleo; la sociedad de instrucción y recreo La lgualdad (abril de 1882) también integrada por negros y mulatos libres. Ya a finales de siglo se fundan otras como La Gloria (189-?), El Porvenir (1893), La Estrella Solitaria (1893) y la prestigiosa sociedad Minerva, en 1899, que dará sus mejores frutos en el aspecto cultural durante la República.

Estas sociedades negras crearon sus propias escuelas, muchas de las cuales eran subvencionadas por el Ayuntamiento, y los profesores que impartían las clases eran en la mayoría miembros de estas instituciones. En su afán por llevar la instrucción a sus socios, estas sociedades negras también tuvieron sus propias publicaciones, como fue el caso de la sociedad «El Progreso», que fundó un periódico de igual nombre; la sociedad "La Amistad", que también contó con su publicación denominada "La Amistad", la sociedad de mujeres «Las Hijas del Progreso» fundó un pequeño periódico del que sólo vieron la luz 15 números y denominado «La Familia».

Importante también dentro de las sociedades cienfuegueras de este período fueron las instituciones creadas por mujeres, en las que la directiva estaba compuesta íntegramente por ellas,tal es el caso de la ya mencionada Las Hijas del Progreso (1879), "aunque hubo algunas como La Caridad de Cienfuegos en 1879 en que el gobierno colonial le vetó el Reglamento, porque no estaba de acuerdo con que a la presidenta se le diera el título de señora como se dijo" ${ }^{14}$.

14 Montejo ArRechea, Carmen Victoria. Sociedades de instrucción y recreo de pardos y morenos que existieron en Cuba Colonial: Periodo 1878 - 1898. Veracruz: Instituto Veracruzano de Cultura, 1993, p. 74. 
Particularmente, desde 1888 en que fue promulgada en Cuba la Ley de Asociaciones, en toda la Isla se fueron constituyendo un gran número de sociedades, gremios, logias masónicas, estas últimas fueron un excelente refugio de la cubanidad.

Esta situación hizo posible que a partir de esta fecha aumentara el número de sociedades existentes en la localidad, no solo de instrucción y recreo, sino también profesionales, religiosas, deportivas, etc. Esto llevó consigo que la cantidad de sociedades que existian se legalizaran oficialmente, lo que trajo como consecuencia que durante ese siglo, la región contara aproximadamente con 133 instituciones, de ellas tres culturales, cinco de recreo, 36 de instrucción y recreo, tres de instrucción recreo y socorros mutuos, dos de socorros mutuos y recreo, tres de instrucción, recreo y beneficencia y una cultural, benéfica y deportiva, las que agrupaban a individuos de una misma clase social y raza. De igual forma, como resultado de esta legislación se fundaron mayor cantidad de sociedades de instrucción y recreo a partir de la década del 80 , coincidiendo esta década con un aumento de la población, así como también una consolidación de la economía en la región. Entre 1840 y 1899 estas llegaron a alcanzar la cifra de 36 , lo que representa un $67,9 \%$ del total de las 53 instituciones que se han podido localizar.

Como respuesta inmediata a la mencionada ley, los cabildos existentes en Cienfuegos tuvieron que legalizarse como sociedades de instrucción y recreo, de beneficencia y socorros mutuos. Es entonces que surgen la sociedad de instrucción y recreo El Espíritu Santo y la Sociedad de instrucción y recreo de naturales de Africa y sus hijos Nación Lucumí, Nuestra Señora de Santa Bárbara.

Marcelino Arozarena en su estudio "Los cabildos de nación ante el registro de la propiedad" señaló: «Estas instituciones de hombres de color, estaban no solo toleradas, sino también autorizadas por las autoridades españolas (...) En Cuba se desarrollaron de manera notable y aún se re-

Es importante señalar, que la investigadora Oilda Hevia Lanier ofrece en su libro El Directorio Central de Sociedades Negras en Cuba 1886-1894, La Habana: Editorial de Ciencias Sociales, 1996, un anexo donde relaciona las sociedades negras de la Isla de Cuba (1878-1894), relación esta que no refleja realmente la cantidad de ellas que existieron en Cienfuegos en esta etapa, salvo los casos de "San Cayetano", "El Progreso", "La Unión Cienfueguera", "Luz de Oriente" y "El Socorro", que sí se mencionan. Existieron además de las que señala la investigadora otras tales como: "El Alba" y el "Club Obrero", de Cruces, "El Alba", de Palmira; "La Igualdad", "Las Hijas del Progreso", "La Amistad", "La Gloria”, "La Estrella Solitaria", "Nuestra Señora de los Desamparados". "Nuestra Señora de Santa Bárbara", "El Espíritu Santo", "La Caridad", «El Centro Africano La Caridad" y "El Porvenir», todas de Cienfuegos. 
cuerdan sus manifestaciones externas y sus fiestas, especialmente la del día de reyes ${ }^{15}$.

Los referidos cabildos tenían su organización y estaban regulados por disposiciones de su libre determinación como lo demuestra Bachiller y Morales en su trabajo Tipos y Costumbres de la Isla de Cuba, cuando dice: «(..) que dichos cabildos formaban sus reglas que guardaba el escribano público del mismo» ${ }^{16}$.

Luego al ser obligados los cabildos a estar empadronados y sometidos a la Ley de Asociaciones para poder sobrevivir, tuvieron que llevar una vida muy ajena a la esencia de su razón de ser ${ }^{17}$.

Sin embargo, a pesar de los esfuerzos que hicieron las directivas de aquellas sociedades, fue imposible la adaptación de los cabildos africanos a aquella legislación,

“(...) por la incapacidad e inconstancia de sus directores para las formalidades escritas y de una administración seria propia de una civilización juridica adelantada, la vida artificial de algunos de estos cabildos sin existencia real o positiva, y la única razón de persistencia de unos pocos: el culto fetichista traído de África" ${ }^{18}$.

\section{Y más adelante agrega:}

«El propósito gubernamental acertadamente anunciado de transformar los cabildos en sociedades modernas, fracasó totalmente. El gobierno se empeñó en atacar las formas externas y articuladas y no se cuidó de observar la persistencia de la esencia interna. Desapareció el cabildo, con lo que de bueno tenía: el socorro mutuo, el seguro contra enfermedades, las bases en fin de una rigurosa mutualidad; desapareció en parte la forma ruidosa del baile de tambores, inofensivo y tan grato al africano; permaneció en cambio semioculto, el fetichismo animista selvático bajo una advocación católica y un reglamento adaptado al formulismo legal» ${ }^{19}$.

\footnotetext{
15 ARozarena, Marcelino. "Los cabildos de nación ante el registro de la propiedad". Actas del folclor 1 (3): 15, marzo de 1961.

16 BaChiller y MORales, Antonio. Tipos y costumbres de la lsla de Cuba. Citado en: (15), p. 16.

17 Al respecto señaló Fernando Ortiz que:

“(...) varias sociedades africanas, supervivencia de los antiguos cabildos, sosteniéndose en fiera lucha por su vida contra la creciente hostilidad y apatia del ambiente social que le es adverso, cobijadas bajo una advocación católica, pero sostenidas por el factor social más misoneísta, por la fe y el rito religioso, por el credo fetichista africano, que confiesan y practican, mal encubierto por una catolización superfcial de idolos lucumies".

Fuente: Arozarena, Ob. cit., p. 16.

18 Los cabildos afrocubanos. Revista Bimestre Cubana XVI (1): 30, enero/febrero de 1921.

19 Idem.
} 
Las directivas de estos cabildos no tenían la cultura e instrucción necesarias para las formalidades escritas, inclusive se proponian objetivos que les era imposible cumplimentar.

Significativa en el contexto de las restantes sociedades cienfuegueras del siglo Xix, resultó ser la sociedad El Artesano. Esta institución fue la de mayor instensidad y grandeza lírica en Cienfuegos durante las décadas del 80 y del 90 , pues gracias al esfuerzo de Anita Aguado y Guillermo Tomás se convirtió en la década del 80 de «una modestísima institución (...) en el Centro Artístico de todo Cienfuegos" ${ }^{20}$. Esta sociedad " contribuyó extraordinariamente a la difusión del arte lírico-dramático, cuya culminación se desarrolla entre los años 1885 al 1889 (Guillermo Tomás los sitúa entre 1882 y 1888) gracias a las iniciativas de Anita Aguado (...)» ${ }^{21}$.

Se está plenamente de acuerdo con esta afirmación después de haberle dedicado un estudio pormenorizado a esta asociación.

"Nacida bajo modestos auspicios, pero gracias al éxito de sus fiestas artísticas, a cuyo reclamo en sus salones, llegó a congregarse lo mejor de la sociedad contemporánea, su prestigio se acrecentó y alcanzó extremos envidiables. El reducido escenario embellecido por el pincel magistral de Salaya, fue el marco feliz de toda una actuación dramática y musical (...) La zarzuela española entonces en todo el apogeo de su fortuna, nutría el repertorio de aquellas fiestas con algunas de sus piezas mejores" ${ }^{22}$.

Se fundó oficialmente el 26 de abril de 1884 y agrupaba a cubanos y a españoles, en su gran mayoría representantes de la clase obrera, aunque también se hallan en la nómina de sus socios, profesionales, periodistas, doctores. Entre sus miembros más destacados se pueden citar a Enrique Edo (valenciano), al Doctor Luis Perna, Pablo Ladislao Rousseau, José Cándido Andreu, Guillermo Tomás y Ana Aguado, por solo mencionar algunos; $y$ de ellos los cuatro últimos vivieron en el exilio neoyorquino y se vincularon a la emigración, prestando servicios a la causa cubana.

En mayo de 1884 comenzó a publicarse el periódico «El Obrero» como órgano oficial de la sociedad "El Artesano", del "Gremio de Toneleros» y de la «Sociedad de Tipógrafos», que respondía a los intereses de la clase

\footnotetext{
20 HeRnANDEZ, Carmen. Biografía de la genial artista y ferviente patriota cienfueguera Ana Carlota de la Cruz Aguado y Andreu de Tomás. Habana: Imprenta y Papelería de Rambla, Bouza y Ca, 1922, p. 33.

21 Historia de la Nación Cubana. T. VII. "La Habana: Historia de la Nación Cubana", S.A., 1952, p. 459.

22 Torre, Miguel Angel DE LA. Prosas varias. La Habana: Editorial de la UH, 1966, p. 384.
} 
obrera. Tuvo una tendencia liberal y defendía la causa de los trabajadores a la necesidad de federación; predicaba constantemente contra la clase burguesa y la explotación. Difundía entre los obreros la necesidad de instruirse y superarse, consideraba la ignorancia de los trabajadores una de las causas principales de que pudieran ser tan explotados y por tanto, abogaba por la instrucción como una de las bases para lograr la emancipación.

En su afán por proporcionar instrucción a sus socios, esta sociedad estableció clases nocturnas, instaló un gimnasio de esgrima y fundó una escuela de pintura y otra de música.

Otra sociedad prestigiosa en la localidad cienfueguera fue la Asociación de Dependientes del Comercio, en cuyo seno abrigó a cubanos y españoles; y se destacaron dentro de ella relevantes figuras de la intelectualidad cienfueguera como fueron, entre otros: José Benigno Nochea Gutiérrez y José Cándido Andreu Cuevas, que fundaron un periódico el Cienfuegos Mercantil, de obligatoria consulta para conocer la economía cienfueguera en la década del 90. También aparecen en sus directivas los nombres de Nicolás Castaño, Nicolás Gamboa, Trino Martínez y Salvador Aja, que eran grandes propietarios de almacenes y del comercio en la localidad.

Producto del espíritu de asociación reinante que ya existía desde mucho antes de establecerse la ley, los chinos residentes en Cienfuegos fundan sus instituciones. Estas fueron el vehículo para mantener sus costumbres y su identidad. El 16 de mayo de 1884 se funda el casino La Gran China, compuesto por chinos inmigrantes que tenían una mejor posición económica y social dentro de su misma clase, y el Casino Asiático, en 1882. En el poblado de Rodas se funda otro Casino Asiático en 1888.

Esta vida asociativa no solo se evidencia en la cabecera de la localidad, sino también en aquellos núcleos poblacionales importantes de la jurisdicción cienfueguera que tenían grandes ingenios azucareros y por consiguiente sus dueños se asentaban allí, como por ejemplo, las zonas de Cruces, Lajas y Rodas. En estos lugares también aparecieron sociedades de instrucción y recreo como: el Círculo de Lajas (1883-84?), el Casino Español de Cruces (1888), el Centro Alfonso XII, el Centro Mercantil de Cruces (1891), el Club Obrero de Cruces (1893), y el Casino Español de Lajas, que existía en 1890; al que estaban vinculados, entre otros, Laureano Falla Gutiérrez, Francisco G. Maymo y Agustín Llorente.

Agustín Serize Medina en su Memoria histórica de Palmira señala que en este poblado, “(...) no existieron sociedades de instrucción y recreo, (...) si bien es cierto, que en el año 1850 (su) padre construyó una casa, que es la que está situada en la calle de Serize esquina a las de Cienfue- 
gos y Escarza, y a la de Villa Clara, hoy de Portela, con el exclusivo objeto de celebrar en ella bailes, que la denominó "Salón Terpsícore", viniendo a ser como una especie de sociedad» ${ }^{23}$.

No sería hasta el año 1880 que se creó la primera institución de este tipo. La fundación de ésta «obedeció al propósito que hubo, desde 1878 de establecerla (...) con el nombre de Las llusiones" ${ }^{24}$.

El Recreo de Palmira ${ }^{25}$ abrió sus puertas a la sociedad palmireña en 1880 , y «dado el entusiasmo de que estaban animados sus socios, prosperó de día en día, al extremo de que ya en 1882 contaba con 76 socios" ${ }^{26}$.

Otras sociedades de este poblado fueron: el Casino Español de Palmira, fundado en 1888 que provenía del antiguo Recreo de Palmira, el Centro de Artesanos de Palmira (1887), la Sociedad de la "raza de color" de instrucción, recreo y beneficencia El Alba, fundada en 1886 y el Liceo, establecido en 1894 e inaugurado el 14 de abril de 1895.

En Rodas se funda el 13 de noviembre de 1899 la sociedad de instrucción y recreo de personas de «color» denominada La Unión, el Liceo el 22 de diciembre de 1898, en 1899 se reorganiza el antiguo Casino Español, estableciéndose la Colonia Española de Rodas.

Es importante señalar que Cienfuegos en 1861 alcanzaba la cifra de 9.950 habitantes y ya para el año 1867 se ha llegado a la suma de 14.012. "La composición étnica de la ciudad en este año es sumamente interesante; un año anterior a la guerra del 68 , tiene un $89 \%$ de su población libre y del total entre libres y esclavos ya sean negros o chinos, sólo el $22 \%$ es de color. En 1870, la población llega a 15.000 habitantes" ${ }^{27}$.

Esta situación se evidencia en las pocas sociedades que se fundaron por esta época.

23 Serize Medina, Agustín. Memoria histórica de Palmira y su partido. La Habana: CNC, 1963 , p. 46.

${ }^{24}$ "La proyectada sociedad "Las llusiones" nunca se llevó a cabo, quedó como su nombre lo indica (...)”. Serize, Ob. Cit., p. 55.

25 «(...) el deseo de fomentar una sociedad de instrucción y recreo tomó cada día más calor en el ánimo de la mayoria del pueblo, determinando los vecinos celebrar la primera reunión con ese objeto, que se llevó a cabo en diciembre de 1879 en la morada del Excapitán D. Primo Martínez (...) a la que denominaron "Recreo de Palmira" (Serize, Ob. cit., p. 72).

26 SeRIZE, Ob. cit., p. 72.

27 Baito Martin, Lilia. Desarrollo urbano de Cienfuegos en el siglo xix. Santiago de Cuba: Universidad de Oriente, Facultad de Artes y Letras, 1989, p. 131 (Tesis en opción del grado científico de Candidato a Doctor en Ciencias de Arte). 
En 1887, «Cienfuegos posee 21.589 habitantes en su casco urbano y es la segunda población de Cuba por su tráfico comercial y por el producto que vende su aduana, la cuarta por su riqueza, número de habitantes e importancia (...)»28.

Como puede observarse, Cienfuegos ha crecido en número de habitantes y es una de las ciudades más importantes de la Isla a fines de siglo. Lógicamente, la mayoría de los hombres de negocio, intelectuales y comerciantes, buscan en la sociedad, el medio para reunirse, asociarse y buscar el esparcimiento y representatividad cultural, de ahí que a partir de los años 80 , el número de sociedades aumente considerablemente.

La última década del siglo XIX repercutió grandemente en el surgimiento de un nuevo tipo de asociación de carácter insurrecto y clubes revolucionarios. Indiscutiblemente, este hecho está íntimamente vinculado al problema de la guerra y la participación de éstas en ella; aunque en los liceos también se conspiró para ayudar al estallido de la Revolución. Entre los clubes que existieron por estos años pueden ser mencionados el «Club revolucionario femenino Cubanita», fundado y dirigido por Rita Suárez del Villar, creado el 3 de mayo de 1896 e integrado totalmente por mujeres y en julio del propio año se fundó el "Club Esperanza del Valle» dirigido por Edelmira Guerra (Esperanza del Valle). Estos clubes no sólo tuvieron una labor importante durante la guerra, sino también algunos como el Esperanza del Valle incluyó en su programa «(...) para cuando llegase la paz, el mejoramiento de la instrucción pública y apoyo a los hombres de ciencia para su mejor desenvolvimiento" 29.

Otros clubes de esta índole fueron: "El Club Incógnito», el "Club Guillermón» y el "Club Esquerra», entre otros.

También en los últimos años del siglo xix se evidencia la penetración de Estados Unidos en el orden económico y sociocultural y esta situación se hace eco en las instituciones cienfuegueras. Ya desde los años $80 \mathrm{co-}$ mienzan a fundarse algunas sociedades, fundamentalmente recreativas y deportivas, cuyos nombres denotan la influencia y el modo de construir de la lengua inglesa. En Cienfuegos aparece el 29 de diciembre de 1889 el "Cienfuegos Sport" y en mayo de 1891, el "Sport Club Cienfuegos".

Por su parte, los Casinos Españoles continuaron haciendo política integrista aunque en términos más moderados. En el caso de Cienfuegos,

8 Idem, p. 134.

29 Academia de Historia de Cuba.Edelmira Guerra "Esperanza del Valle: Una de las más valiosas auxiliares en la guerra del 95". La Habana: /s.n./, 1953, p. 27. 
cuando España pierde su poderío sobre Cuba, todas las sociedades regionales españolas deciden fusionarse al Casino.Al cesar el dominio secular de España en Cuba y después de zarpar del puerto de Cienfuegos el último vapor que repatriaba a los soldados y oficiales, "se dejó sentir las consecuencias de las condiciones políticas que surgían del nuevo estado de derecho, la conveniencia para los españoles residentes en Cienfuegos, de agruparse para estrechar aún más los vínculos de solidaridad moral y atender a sus intereses sociales y económicos" ${ }^{30}$.

Estas sociedades «aportaron todos los bienes que poseían, sus créditos activos y pasivos, y el efectivo de sus cajas (...) formando en virtud de esta sólida y oportuna fusión, la sociedad Casino Español de Cienfuegos, Centro de la Colonia Española, que fue la primera colonia establecida en Cuba, y cuya preminencia ostentaba con orgullo esa institución" (sic) ${ }^{31}$. El local social de esta institución estaba ubicado en San Fernando esquina a San Luis.

De modo general, la mayoría de las instituciones y asociaciones cienfuegueras del siglo XIX favorecieron el desarrollo cultural y artístico-literario en la región, y para ello sus directivas se trazaron metas y fines que cumplían llevando a la práctica vías y acciones que repercutían positivamente en pro del adelanto sociocultural de los miembros y familiares que pertenecían a las diferentes sociedades. Estos centros fueron verdaderos exponentes del desarrollo de la cultura en la región con el establecimiento de cátedras, escuelas, veladas filarmónicas, juegos florales, tertulias y certámenes literarios, creación de salas teatrales, conciertos y veladas liricas, entre muchas otras funciones recreativas, que a la par del recreo, llevaban implícitas la creación y la divulgación de la cultura en todos los órdenes.

30 Gonzalez Contreras, J. M. Reseña histórica y cronológica de la colonia española de Cienfuegos y su sanatorio. Cienfuegos: Imprenta San Carlos 129 /s.a/, p. 7.

31 Idem, p. 8. 